\title{
Dabrowski’s Overexcitabilities Profile among Gifted Students
}

\author{
Aliza Alias ${ }^{1}$, Saemah Rahman ${ }^{1}$, Rosadah Abd Majid ${ }^{1} \&$ Siti Fatimah Mohd Yassin ${ }^{2}$ \\ ${ }^{1}$ Faculty of Education, Universiti Kebangsaan Malaysia, Selangor, Malaysia \\ ${ }^{2}$ Pusat PERMATA pintar, Universiti Kebangsaan Malaysia, UKM Bangi Selangor, Malaysia \\ Correspondence: Aliza Alias, Faculty of Education, Universiti Kebangsaan Malaysia, 43600 UKM Bangi, \\ Selangor, Malaysia. Tel: 60-3-8921-6273. E-mail: eliza@ukm.my
}

Received: August 16, 2013 Accepted: October 14, 2013 Online Published: November 28, 2013

doi:10.5539/ass.v9n16p120 URL: http://dx.doi.org/10.5539/ass.v9n16p120

\begin{abstract}
This study was conducted to identify the overexcitabilities profile of gifted students. The Dabrowski's concept of overexcitabilities is the heightened intensity and sensitivity displayed in the gifted students' behaviours when responding to the stimuli in the environment. These characteristics give a negative impression that these students have behaviour or disciplinary problems. Dabrowski had identified five domains of overexcitabilities which are psychomotor, sensual, imagination, intellectual and emotional. The presence of overexcitabilities in gifted students is measured by using the Self-Assessment Overexcitabilities instrument. The findings showed that $88 \%$ of the gifted students have at least one high level of overexcitabilies. The findings also identified four profiles of gifted students' overexcitabilities which displayed very distinct level of intensities across the five domains. The profiles' characteristics are (i) Profile 1 - high imagination; (ii) Profile 2 - all domains are high; (iii) Profile 3 high psychomotor, (iv) Profile 4 - all domains are low. It also showed that not all gifted students have high overexcitabilies as proven by Profile 4. It is concluded that, even though the gifted students have almost the same level of intelligence, but they have different characteristics of overexcitabilities.
\end{abstract}

Keywords: overexcitabilities, gifted students

\section{Introduction}

A student who shows higher academic achievement and advanced intellectual development compared to his peers is considered as a gifted student. However, gifted students with similar intellectual achievements do not necessarily share the same interests, personality, abilities, and characteristics. Each gifted student is unique and different from each other in terms of their intellectual, physical, social, as well as emotional development (Daniels \& Meckstroth, 2009). One of the characteristics of giftedness that caught the attention of educational psychologists is the extreme intensity and sensitivity in the gifted student's behaviour. These heightened and intense characteristics are known as overexcitabilities and are claimed as universal characteristics of gifted individuals (Webb et al., 2005).

The concept of overexcitabilities was introduced to the world of giftedness by Dabrowski in 1967 (Daniels \& Piechowski, 2009). It has drawn many researchers to venture into identifying the presence of overexcitabilities among gifted and talented students (Gross et al., 2007; Tieso, 2007a, 2007b; Bouchard, 2004; Mendaglio, 2003; Piechowski, 1999; Ackerman, 1997). The findings supported the claim that overexcitabilities were part of the gifted students' characteristics. Moreover, the extreme intensity and sensitivity influenced the students' actions, personalities, way of thinking, and also emotion (Webb et al., 2005), up to a point that they might be labelled as nerd or unusually strange by their peers (O'Connor, 2002).

Unfortunately, overexcitabilities have been found to affect the personalities of gifted students in a negative way that made their peers feel uncomfortable in the learning process (Smith et al., 2004). If this phenomenon is not given a fair attention, it would affect the gifted students' social and emotional functions (Webb et. al, 2005). Besides that, overexcited reactions displayed by these students towards their learning environment (Smith et al., 2004) could negatively affect social interactions and communication in the learning process. Therefore, it is crucial for teachers to understand and aware of the concept of overexcitabilities in gifted students' behaviours so that the students' needs in the learning environment were wisely attended to (Webb et al., 2005).

Furthermore, Treat (2006) stated that overexcitabilities influenced the students' high level of sensitivity, awareness, and intensity in related areas of interest. For example, they are highly creative work in the field of 
arts, very competitive in the field of sports, and also showing outstanding leadership characteristics in completing a given task. Overexcitabilities were also demonstrated by gifted individuals through intense level of energy, deep appreciation of something they were passionate with, vivid imagination, and strong sensual reactions when responding to stimulus (Silverman, 2009; Whitney \& Hirsch, 2007). Unfortunately, according to Piechowski (1997), the stronger the overexcitabilities were, the less their peers and teachers were able to accept them in the learning environment and social interaction circles.

Nevertheless, a student's reactions towards stimulus in any given situation varied depending on his or her five overexcitabilities which are psychomotor, sensual, intellectual, imagination, or emotional. The characteristics for these domains are vastly different from each other. For example, intense behaviour such as speaking very rapidly and fidgetiness (psychomotor), intensely fussy over food and other sensory input from environment (sensual), easily absorbed into fantasy world due to creative imagination (imagination), always asking challenging questions that irritates the class (intellectual) and easily breaking down to tear when being scolded or criticized (emotional) could create uncomfortable situation in the learning environment (Bailey 2010; Rizza \& Morrison, 2003).

Therefore, teachers with limited knowledge of overexcitabilities might assume that the disruptive behaviours displayed as disciplinary problems (Rotigel, 2003). Rotigel further described that the knowledge and understanding of the concept of overexcitabilities of gifted students should help the teachers to be more aware in fulfilling the students' social, emotional as well as their cognitive needs during the teaching and learning process. In addition, the teachers should accept the characteristics of overexcitabilities as assets in optimising the gifted students' potentials in related fields to the domains of overexcitabilities. Hence, Daniels and Meckstroth (2009) stressed that the innate intensity in gifted students should be considered as positive way to stimulate their existing potentials not as an emotional or behavioural problem (Bouchard, 2004; Piechowski \& Miller, 1995).

This is due to the fact that overexcitabilities can be used to identify the gifted students' potentials based on their domains of overexcitabilities. For example, gifted students who show the following characteristics have potentials in the respective fields: i) psychomotor overexcitability would bring out potential in the field of sports or extreme and challenging sports; ii) sensual overexcitability with high sensitivity to taste buds reflects the potential in the field of culinary arts; iii) imagination overexcitability shows potential in the field of performing or visual arts or creatively produce outstanding inventions; iv) intellectual overexcitability is essential in developing potentials academic fields such as science and technology; and finally v) emotional overexcitability would bring out the sensitivity towards potentially in the of social activities that concerns with the wellbeing of the human civilisation.

Therefore, overexcitabilities should be accepted as part of the gifted students' personalities that should be understood, stimulated, and also supported to ensure a healthy development of their potentials (Daniels \& Meckstroth, 2009), rather than being labelled and punished as behavioural or problematic problems.

\section{Objective}

The objective of this study is to identify the overexcitabilities profile of gifted students.

\section{Methodology}

The sample of this research was purposely selected from group of participants of a school holiday camp for gifted children at a local university in Malaysia. There were 335 students ranging between 10 to 15 years of age, who completed an Overexcitability Self-Evaluation questionnaire in the Malay Language. The questionnaire was a translation of The Overexcitabilities Questionnaire II which was developed by Falk, Lind, Miller, Piechowski and Silverman in 1999. The reliabilities of each domains are high with Cronbach's alpha coefficient for all five domains over 0.7 i.e. psychomotor $(0.83)$, sensual $(0.80)$, imagination $(0.86)$, intellectual $(0.88)$, and emotional (0.75).

The questionnaire was used to gather data on the respondents' own perception of the statements given. The data was analysed descriptively to identify the presence of overexcitabilities in gifted students. Students that show low level of overexcitabilities indicated that they do not have any overexcitabilies. While moderate level of overexcitabilities is considered as having overexcitabilities with the tendency to react and show some intensity in the students' behaviours. The high level of overexcitabilities definitely shows that the students have very intense reactions in their actions. An analysis of K-Means cluster was used to identify the overexcitabilities profiles based on the score gathered in the questionnaire.

\section{Findings}

The findings of this research showed that $88 \%$ of the gifted students in this study have at least one domain of 
overexcitabilities. According to Piirto (2010), students who score 3 or above, with 3 being the mean, indicating the presence of overexcitabilies. Further, from cluster analysis, four different profiles of overexcitabilities among gifted students have been identified. Table 1 below, shows the number of students for each profile and also the distinct characteristics that represent the profiles which are labelled as Profile 1, Profile 2, Profile 3, and Profile 4.

Table 1. Students' overexcitability profile characteristics

\begin{tabular}{ccl}
\hline Profile & Number of students & \multicolumn{1}{c}{ Overexcitabilities Characteristics } \\
\hline Profile 1 & 87 & High level of imagination \\
Profile 2 & 78 & All domains of overexcitabilities are high \\
Profile 3 & 82 & High level of psychomotor \\
Profile 4 & 88 & All domains of overexcitabilities are low \\
\hline
\end{tabular}

The first profile of overexcitabilities, showed that 87 group of gifted students has high overexcitability imagination. While, Profile 2 showed that 78 gifted students who have all domains of overexcitabilities at high level. In contrast with Profile 1, 82 gifted students in Profile 3 displayed a high psychomotor overexcitability and finally, the last profile of overexcitabilities has grouped 88 gifted students who have low level of all overexcitabilities. As was stated before, these gifted students in Profile 4 who have low level of overexcitabilities indicated that they do not have any overexcitabilies. Interestingly, this study found that a group of gifted students who have almost the same level of intelligence, showed contrast overexcitabilities characteristics from each other, namely between Profile 1 and Profile 3; and also between Profile 2 and Profile 4.

\section{Discussion}

Being gifted does not mean the individual has high intensity or sensitivity in his or her behaviour. Nonetheless, students who have at least one domain of overexcitabilities supported Dabrowski's notion that overexcitabilities are prevalent in gifted students (Piechowski, 1999). As gifted students are unique in their own ways, their profile of overexcitabilities also varies depending on the different combination of the five domains at its perspective levels. Each profile displayed different overexcitabilities characteristics that reflected possible reactions in the students' behaviours. Hence the four profiles identified in this study were different from four profiles of overexitabilities in Rinn, Mendaglio, Rudasill, McQueen (2010) research. The notably differences are due to the characteristics of the sample in each research, the combination of domains based on the level of each overexcitabilities.

Based on the distinct characteristics of each profile, it is undoubtedly that gifted students in Profile 1, who have high level of overexcitability in imagination, could be potentially creative beyond the capabilities of an adult. This creativity would be an evident in performing arts activities or any area of interest that encourages them to be innovative. They also tend to produce outstanding piece of art or ideas as known gifted individuals like Albert Einstein or Walt Disney (Daniels \& Piechowski, 2009). However, they are easily bored in the classroom if the learning process does not interest them at all. They could become creatively disruptive in the classroom or just keep to themselves doing what interest them such as drawing or write poems.

Similarly for students in Profile 3, their abundant physical energy could disrupt the classroom as they need to discharge the energy through action. These students have the tendency to move impulsively and spontaneously in an effort to release their overwhelmed inner energy (Daniels \& Meckstroth, 2009). Sometimes they are labelled as hyperactive or ADHD (attention deficits hyperactive) because they are very disruptive in the classroom (Amend, 2009). Nevertheless, this high psychomotor energy can be channelled towards activities that require fast and intense movements in extreme sports such as skateboarding, as well as fast-paced dancing and martial arts. These students should be trained as potential athletes as they are very competitive and tend to give it all in whatever they are doing. Unfortunately, these students are prone to depression as they are unable to cope with loss or failure (David \& Meckstroth, 2009).

As for Profile 2, the high level of overexcitabilies in all domains would display complex personalities. This is due to the fact that their responses and reactions towards stimulus around them are different according to their level of intensity. The complexity of their personalities could also pose some serious problems in the students' life as their intensities cut across all five domains of overexcitabilities (Jackson \& Moyle, 2009). Hence, in order to retain balance and harmony in the learning environment between these students and their peers in the 
classroom, the teachers need to be creative in optimizing these students' unique personalities in developing their potentials wisely in the learning process (Jackson \& Moyle, 2009) by varying teaching strategies.

Contrarily, Profile 4 proved that there are gifted students who do not possess any overexcitability. However, this does not mean that they are not gifted. These students were already identified as gifted students which qualified them to participate in the holiday camp for gifted students. Their scores in intelligence test reflect their high level of intelligence. According to Daniels and Meckstroth (2009), Dabrowski had stated that an individual who possesses more than one overexcitability characteristic is a gifted and talented individual. This showed that an individual could be gifted even though he or she does not have overexcitability.

Anyway, these extreme intensity and sensitivity characteristics of gifted students should be used as an asset in developing the students' potentials. It also should be utilised in assisting gifted students' social, cognitive emotional, and personality development (Whitney \& Hirsch, 2007). The effect of overexcitability depends on its strength or level of intensity. Each intensity contributes to a different response to the stimulus received by the students (David \& Meckstroth, 2009), either positively or negatively. This is because each domain of overexcitability could deeply affect the students' development in different ways. Therefore, teacher and parents need to be aware of this risk and how it interferes with the development of gifted children (Rosadah \& Aliza, 2010). Each intensity and sensitivity characteristics must be identified and understood carefully so that the teacher could optimize the students' potential.

Moreover, Dabrowski claimed that intellect, imagination and emotion have more positive impact in the individual's potential development Mendaglio (2012). According to David and Meckstroth (2009), intellectual overexcitability is the characteristic most often associated with gifted students. But intellectual overexcitability refers to a student's curiosity and passion for leaning. And combine with imagination, overexcitabilities could often cause problems in the teaching and learning process as high curiosity and creative suggestions sometimes challenges the teacher capabilities. The teacher also should not underestimate the potentials of the gifted students if they do not show excellent academic achievement. Even though, with tendency of working on a problem until it is solved but if they were not interested, they would fail to achieve to their real potential in academic. Therefore, teachers must be prepared to provide extra work to such students in order to stimulate and challenge their mind to a higher level.

A domain that should be focused on in the concept of overexcitability is emotion because it is an important component in the development and formation of healthy personalities among gifted students. Whitney and Hirsch (2007) believed that emotional overexcitability is an important component in the development of gifted students' innate potential because emotions control an individual's actions and thoughts, leading him to make a decision that is within moral grounds. However, emotional overexcitability also negatively affects a student's development; for example, extreme feelings of love or affinity towards a person, an animal or even abstract things. This includes a deep interest in a particular field which causes him to reject trying other things. The research findings show that there is a group that displayed high overexcitability in all five domains, including emotion (from the Profile 2 group). Teachers must turn their attention to the students in this group and help them cope with their extreme emotions so that they will not let their feelings get the best of them as they are prone to depression and other emotional problems.

\section{Conclusion}

Gifted students who are frequently labelled as problematic because of their intense behaviour should be given assistance in understanding and coping with their overexcitabilities. This would help them to control and channel their intensity and sensitivity in a positive and meaningful way. Knowing the characteristics of these overexcitabilities will prepare the teachers and parents of these overexcited students to minimize the conflict among the gifted students with their peers and teacher or parents (Rosadah \& Aliza, 2010). The high intensity and sensitivity shown by these gifted students are part of their personalities. Therefore the teacher should treat it as an asset in developing their potentials or interests in related fields to their overexcitabilities. In conclusion, the concept of overexcitabilities that are prevalent in gifted students, need to be addressed not only by the teachers but also the parents of the students. This is due to the fact that they play important roles in the development of the students in both settings, at school and at home.

\section{References}

Ackerman, C. M. (1997). Identifying gifted adolescents using personality characteristics: Dabrowski's Overexcitabilities. Roeper Review, 19(4), 229-236. http://dx.doi.org/10.1080/02783199709553835

Amend, E. R. (2009). Dabrowski Theory: Possibilities and implications of misdiagnosis, missed diagnosis, and 
dual diagnosis in gifted individuals. In S. Daniels, \& M. M. Piechowski (Eds.), Living with intensity (pp. 33-56). USA: Great Potential Press Daniels.

Bailey, C. L. (2010). Overexcitabilities and sensitivities: Implication of Dabrowski's Theory of Positive Disintegration for Counselling the Gifted. Retrieved from http://counselingoutfitters.com/vistas/vistas10/Article_10.pdf

Bouchard, L. L. (2004). An instrument for the measure of Dabrowskian overexcitabilities to identify gifted

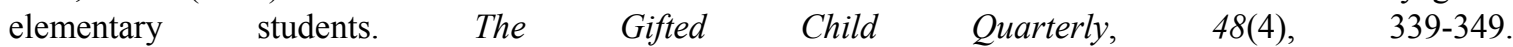
http://dx.doi.org/10.1177/001698620404800407

Daniels, S., \& Meckstroth, E. (2009). Nurturing the sensitivity, intensity, and developmental potential of young gifted children. In S. Daniels, \& M. M. Piechowski (Eds.), Living with intensity (pp. 33-56). USA: Great Potential Press Daniels.

Daniels, S., \& Piechowski, M. M. (2009). Embracing Intensity: Overexcitablity, Sensitivity and the Developmental potential of the gifted. In S. Daniels, \& M. M. Piechowski (Eds.), Living with intensity. USA: Great Potential Press.

Falk, R. F., Lind, S., Miller, N. B., Piechowski, M. M., \& Silverman, L. K. (1999). The Overexcitabilities Questionnaire II(OEQII). Denver, CO: Institute for the Study of Advanced Development.

Gross, C. M., Rinn, A. N., \& Jamieson, K. M. (2007). Gifted Adolescents' overexcitabilities and self-concept: An analysis of gender and grade level. Roeper Review, 29(4), 240-248. http://dx.doi.org/10.1080/02783190709554418

Jackson, P. S., \& Moyle, V. F. (2009). With Dabrowski in Mind: Reinstating the Outliers in Support of Full-Spectrum Development. Roeper Review, 31, 150-160. http://dx.doi.org/10.1080/02783190902993607

Majid, R. A., \& Alias, A. (2010). Consequenses of risk factor in the development of gofted children. Procedia Social and Behavioral Science, 7, 63-69. Retrieved from http://www.sciencedirect.com/science/article/pii/S1877042810020148 http://dx.doi.org/10.1016/j.sbspro.2010.10.010

Mendaglio, S. (2003). Heightened multifaceted sensitivity of gifted students. The Journal of Secondary Gifted Education, 14(2), 72-82.

Mendaglio, S. (2012). Overexcitabilities and giftedness research: A call for a paradigm shift. The Journal for the Gifted, 35(3), 207-219.

O'Connor, K. J. (2002). The application of Dabrowski's Theory to the gifted. In M. Neihart, S. M. Reis, N. M. Robinson, \& S. M. Moon (Eds.), The Social and Emotional Development of Gifted Children (pp. 51-60). Washington: Prufrock Press Inc.

Piechowski, M. M. (1997). Emotional Giftedness: The Measure of Intrapersonal Intelligence. In N. Colangelo, \& G. A. Davis (Eds.), Handbook of Gifted Education (2nd ed.). USA: Allyn \& Bacon.

Piechowski, M. M. (1999). Overexcitabilities. Encyclopaedia of Creativity, 1(2), 325-334.

Piechowski, M. M., \& Miller N. B. (1995). Assessing developmental potential in gifted children: A comparison of Methods. Roeper Review, 17, 176-180. http://dx.doi.org/10.1080/02783199509553654

Rinn, A. N., Mendaglio, S., Rudasill, K. M., \& Mc Queen, K. S. (2010). Examining the relationship between the overexcitabilities and self-concepts of gifted adolescents via multivariate cluster analysis. The Gifted Child Quarterly, 54(1), 3-17. http://dx.doi.org/10.1177/0016986209352682

Rizza, M. G., \& Morrison, W. F. (2003). Uncovering stereotypes and identifying characteristics of gifted and students with emotional/behavioral disabilities. Roeper Review, 25, 73-77. http://dx.doi.org/10.1080/02783190309554202

Rotigel, J. V. (2003). Understanding the young gifted child: Guidelines for parents, families, and educators. Early Childhood Education Journal, 30(4), 209-214. http://dx.doi.org/10.1023/A:1023331422963

Silverman, L. K. (2009). My love affair with Dabrowski's Theory: A personal odyssey. Roeper Review, 31(3), 141-149. http://dx.doi.org/10.1080/02783190902993912

Smith, T. E. C., Polloway, E., Patton, J. R., \& Dowdy, A. D. (2004). Teaching students with special needs: In inclusive setting (4th ed.). USA: Pearson Education.

Tieso, C. L. (2007a). Overexcitabilities: A new way to think about talent. Roeper Review, 29(4), 232-239. 
http://dx.doi.org/10.1080/02783190709554417

Tieso, C. L. (2007b). Patterns of overexcitabilities in identified gifted students and their parents. The Gifted Child Quarterly, 51(1), 11-22. http://dx.doi.org/10.1177/0016986206296657

Treat, A. R. (2006). Overexcitabilities in gifted sexually diverse population. The Journal of Secondary Gifted Education, 27(4), 244-257.

Webb, J. T., Amend, E. R., Webb, N. E., Goerss, J., Beljan, P., \& Olenchak, F. R. (2005). Misdiagnosis and dual diagnosis of gifted children and adults: ADHD, Bipolar, OCD, Asperger's Depression, and other Disorders. USA: Great Potential Press, Inc.

Whitney, C. S., \& Hirsch, G. (2007). A love for learning: Motivation and the gifted child. USA: Great Potential Press.

\section{Copyrights}

Copyright for this article is retained by the author(s), with first publication rights granted to the journal.

This is an open-access article distributed under the terms and conditions of the Creative Commons Attribution license (http://creativecommons.org/licenses/by/3.0/). 